\section{Support for corporate providers and groups}

The Association of Dental Groups (ADG) is a leading support system for corporate dentistry providers and dental groups which is dedicated to ensuring the delivery of quality outcomes for patients and working with the profession to improve patient care.

As well as supporting the Government's aims to improve high quality access to dental care, the ADG ensures that members meet the highest of standards in order to deliver exceptional patient care and treatment. The ADG says it takes pride in working with corporate providers and dentistry groups and will continue to work hard to meet its aims and objectives.

Paul Critchley, Managing Director of Smile:Together said of his decision to join the ADG: 'We joined the ADG for two reasons. The first was that we wanted to share and better understand some of the issues we face by working with peers in similar business structures to ourselves.

'Two heads are always better than one when seeking solutions to industry-wide challenges that affect our patients and the ADG provides a source of shared knowledge.

'The second reason was that we wanted to join an organisation that had an influential voice on these matters. In a care profession like dentistry where political or operational decisions are being made about your sector, it's useful to be able to contribute and we now have a far greater influence than we would as a stand-alone group in a rural part of the country'

The ADG says it is dedicated to improving dental access for patients across the country and cites the example of the Essex team from ADG member Community Dental Services (CDS) CIC.

CDS recently partnered with Southend Clinical

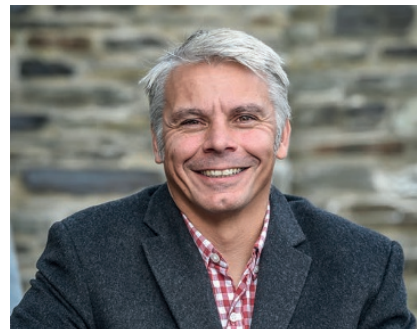

Paul Critchley, MD of Smile:Together Commissioning Group to produce a series of flash cards to be used by local dentists to improve treatment explanations to patients. Designed to help people with a reduced understanding and alleviate anxiety, it is hoped that the resource will be extended across Essex and Thurrock Local Authority.

Lorraine Mattis, Operations Director for CDS in Essex, said: 'It is CDS' mission to provide oral health in evermore communities so it is important for us to work with partners to do whatever we can to provide oral health advice and support people with additional needs to visit the dentist. Providing information that is easier to understand is a very important part of reducing anxiety.'

More information about the ADG is available at www.dentalgroups.co.uk.

\title{
Efficient, simple and clever technology
}

Practitioners are praising the ORTHOPHOS SL 3D all-rounder $\mathrm{X}$-ray device from Clark Dental. The ORTHOPHOS SL 3D facilitates every practice workflow, offering incredibly sharp 2D panoramic images with its DCS sensor and Sharp Layer Technology, and full 3D volume flexibility due to its selectable fields of view and easier, more secure patient positioning for the perfect image.

Dr Claudio Peru, from Chiswell Green Specialist Dental Centre in St Albans, said: 'The ORTHOPHOS SL 3D has improved our workflow considerably.

'We now work much more efficiently and the imaging unit has increased patient conversion rates as we are able to offer more services onsite during initial appointments.

'One of the most useful features of the technology for me is the High Definition imaging mode, which is useful for diagnosing and treatment planning endodontic cases. I also like that the OPG set up is extremely simple with the machine recognising the occlusal plane automatically.

'In addition, the customer service from Clark Dental had been fantastic with a prompt response whenever we've had questions while getting used to the machine. I would 100\% recommend the ORTHOPHOS SL 3D and Clark Dental to others.'

To find out more about the ORTHOPHOS SL 3D, contact Clark Dental on 01268733 146, or email info@clarkdental.co.uk or visit www.clarkdental.co.uk.

\section{Restoration retention system}

Filhol Dental is promoting its FILPOST product described as the only prefabricated post system that can be customised to suit the restoration for root post and core build up.

It can be bent and shortened without risk of fracture, enabling easy insertion of multiple posts into converging canals and is engineered to be easier to place, even in difficult cases, in a faster, safer manner.

There is more preserving of healthy tooth structure and it is stronger in use via its unique passive 'interlocking' system, says the company. The product is $99.8 \%$ titanium, biocompatible and compatible with all dental materials. No drilling is required during placement thus avoiding risk of perforation, and its anatomical shape minimises dentine removal.

Retention grooves along the post, working together with retention grooves formed within the canal surface, by the special Universal Groover, create a unique passive interlock that strengthens retention.

Another company product is FILPIN. The self-threading, selfaligning FILPIN speeds and eases placement for self-shearing first time, every time, once optimum depth is reached.

After insertion, FILPIN can be easily bent to suit the restoration without breaking it or the tooth, says the company. Its unique thread design maximises retention strength without causing internal stresses that may lead to cracking or crazing. FILPIN enhances retention of all types of restorations to dentine.

More information is available at www.filhol.com or by emailing info@filhol.com. 